\title{
Survival in Patients Treated by Long-term Dialysis Compared With the General Population
}

\author{
Maurizio Nordio, MD, MSc(Epid), ${ }^{1}$ Aurelio Limido, $M D,{ }^{2}$ Umberto Maggiore, $M D, P h D,{ }^{3}$ \\ Michele Nichelatti, BSc, PhD, ${ }^{4}$ Maurizio Postorino, $M D,{ }^{5}$ and \\ Giuseppe Quintaliani, MD, ${ }^{6}$ on behalf of the Italian Dialysis and Transplantation
}

Registry*

\begin{abstract}
Background: Relative survival, a methodology previously used in epidemiologic studies of cancer, compares the observed survival of a patient cohort with expected survival derived from general population life tables. We examined relative survival in patients treated by long-term dialysis in the Italian Dialysis and Transplantation Registry in order to determine the prognosis of dialysis patients.

Study Design: Cohort study drawn from a registry.

Setting \& Participants: Patients enrolled in the Italian Dialysis and Transplantation Registry.

Factors: Sex, age, primary kidney disease, renal replacement therapy modality, and main comorbid conditions. Outcomes: Death from any cause.

Measurements: Relative survival ratio (the ratio of observed survival in the population of interest to the survival expected given the age- and period-specific mortality of the general population) and excess mortality rate (difference between observed and expected mortality rates).

Results: In January 2000 to December 2008, a total of 27,642 patients were included. The 5-year relative survival estimate was $55.6 \%(95 \% \mathrm{Cl}, 54.7 \%-56.5 \%)$. The excess mortality rate showed a peak at 3 months $(21$ deaths/100 patient-years), then decreased, becoming constant from the end of year 1 to year 8 , with leveling off at about 10 deaths/100 patient-years. Older age, systemic diseases, and diabetes showed the strongest association with excess mortality. Peritoneal dialysis was associated with a lower relative excess risk in only the first year of treatment.

Limitations: The patient cohort comprises about half the Italian patients beginning dialysis therapy in the period.

Conclusions: This study highlights the applicability of relative survival methods in dialysis patients. This measure allows estimation of disease prognosis and severity comparisons among chronic diseases. The excess mortality rate appears to be a more sensitive and informative measure than the simple proportion of survivors.

Am J Kidney Dis. 59(6):819-828. @ 2012 by the National Kidney Foundation, Inc.
\end{abstract}

INDEX WORDS: Relative survival; excess mortality rate; dialysis registry.

$\mathbf{M}$ ortality in dialysis registries usually is defined by cause-specific or all-cause mortality. ${ }^{1,2}$ With the first method, deaths are attributed to a specific disease, while all other causes are censored. In contrast, all-cause (or crude) mortality includes all deaths within the cohort being studied without distinguishing those caused by the disease of interest from those arising from other factors. The main limitation of cause-specific mortality is that it provides useful information only if the registered causes of death are reliable; this usually is not the case for dialysis registries or, in general, observational studies. ${ }^{3}$ However, all-cause survival analysis is limited by the failure to discriminate between deaths due to the disease of interest and deaths due to other causes. In general, these approaches are not very useful for estimating prognosis in renal replacement therapy patients due to lack of comparisons with the general population.

Chronic kidney disease rarely is considered a cause of death; rather, it commonly is perceived as a factor that enhances the effect of other causes ${ }^{4}$ such as heart diseases and infections. Thus, it is difficult to determine the prognosis of patients treated by long-term dialysis.
From the ${ }^{I}$ Nephrology and Dialysis Unit, ULSS 15, Camposampiero-Cittadella, Padua; ${ }^{2}$ Nephrology and Dialysis Unit, Azienda Ospedaliera Fatebenefratelli e Oftalmico, Milan; ${ }^{3}$ Department of Clinical Medicine, Nephrology and Health Care, Parma University, Parma; ${ }^{4}$ Service of Biostatistics, Niguarda Ca' Granda Hospital-Milan, Milan; ${ }^{5}$ Nephrology, Dialysis and Transplantation Unit and CNR-IBIM Clinical Epidemiology and Pathophysiology of Renal Diseases and Hypertension, Reggio Calabria; and ${ }^{6}$ Department of Nephrology-Dialysis, Silvestrini Hospital, Perugia, Italy.

\footnotetext{
* Members of the Italian Dialysis and Transplantation Registry are listed in the Acknowledgements.

Received July 30, 2011. Accepted in revised form December 12, 2011. Originally published online February 24, 2012.

Address correspondence to Maurizio Nordio, MD, MSc(Epid), Nephrology and Dialysis Unit, P. Cosma General Hospital, 35012 Camposampiero(Padua), Italy.E-mail: maurizio.nordio@gmail.com (C) 2012 by the National Kidney Foundation, Inc.

0272-6386/\$36.00

doi:10.1053/j.ajkd.2011.12.023
} 
In cancer registries, this problem was solved by analyzing relative survival instead of cause-specific or crude survival. This methodology matches the survival of patients with a specific malignancy with that of a standard reference population (usually life tables of a national or regional population). The relative survival method relies on the assumption that the prevalence of the disease is low and has little impact on overall estimates. Chronic kidney disease fulfills this assumption because it has negligible impact on all-cause mortality in the general population. If we compare the mortality of a cohort of dialysis patients with that of a matched cohort extracted from the general population, the only factor that distinguishes these individuals is dialysis therapy; thus, any mortality excess observed may be safely attributed to this factor.

We used the relative survival method to estimate the decrease in survival directly due to dialysis therapy in patients of the Italian Dialysis and Transplantation Registry (IDTR) in order to estimate their prognosis. Moreover, we tried to identify special subgroups of patients at high risk of death in order to uncover which patients should be the focus of research aimed at ameliorating prognosis.

\section{METHODS}

Our analysis is based on data from the IDTR. We performed a cohort study by selecting all patients starting hemodialysis or peritoneal dialysis therapy from January 1, 2000, to December 31, 2008 , in Italy. Changes in treatment modality or death were registered until December 31, 2008. Only patients coming from Italian regions able to provide complete follow-up information were enrolled, no other eligibility criteria were applied.

Data were collected in accordance with Italian law; the IDTR is an anonymous collection of regional registries, instituted by regional laws. Informed consent is requested from patients starting dialysis therapy to allow for data collection within the framework of the registries and provision of these data to the IDTR in an anonymous form.

Data considered in this study were date of first treatment, sex, age (divided into 5 classes: $<25,25-45,45-65,65-75$, and $\geq 75$ years), primary kidney disease (grouped into congenital and hereditary disease, diabetes, primary glomerulonephritis, pyelonephritis, systemic diseases, vascular, unknown, and others), prevailing dialysis modality (hemodialysis and peritoneal dialysis), kidney transplant, main comorbid conditions (heart disease, heart failure, cerebral vascular disease, peripheral vascular disease, diabetes, chronic lung disease, cancer, and hypertension) defined according to, ${ }^{5}$ death, and date of death. The outcome was death from any cause.

For each patient, survival was calculated from the first dialysis treatment to death or to December 31,2008, if alive at the end of follow-up. If the patient shifted from peritoneal dialysis to hemodialysis therapy or vice versa, he or she was assigned to the longer-lasting treatment. Successful kidney transplant recipients and lost patients were censored at the date of the last scheduled dialysis session.

Information bias could occur for incomplete reporting of the outcome, leading to overestimation of survival. Therefore, we compared mortality rates among Italian regions, but did not find significant differences. The kidney transplant rate was similar to the value provided by the National Transplantation Center. The number of patients lost to follow-up was negligible.

The number of cases in the Italian regions with complete follow-up in the study period determined sample size.

Relative survival (the ratio of observed survival in the group of interest to expected survival based on the age- and period-specific mortality of the general population from which the group was derived $^{6}$ ) can be calculated from the life table of the general population. In this case, the study sample comprised IDTR participants who began dialysis therapy in 2000-2008 and the reference population was the total Italian population of the same age and sex. The basic assumption is that the expected mortality experienced by the study sample during a particular period would be the same as mortality in the general population.

First, the population $(l)$ at the start of each interval in each yearly cohort and the number of deaths $(d)$ and those lost to follow-up $(w)$ during the interval were determined. The population at risk $\left(l^{\prime}=l\right.$ $-(w / 2))$ and interval-specific survival $\left(p=1-\left[d / l^{\prime}\right]\right)$ were estimated by assuming withdrawals and deaths were distributed evenly over the interval.

Cumulative survival $(C P)$ for a particular interval $(i)$ then was obtained by the cumulative product of the interval-specific survival, where the initial cumulative survival $(C P[0])$ was equal to 1 and $C P(i+1)=C P(i) \times p(i)$.

Expected survival probabilities $\left(p^{*}\right)$ were obtained from Italian population life tables ${ }^{7}$ by multiplication of the published annual probabilities of survival. The appropriate probability, depending

Table 1. Baseline Characteristics of Dialysis Patients

\begin{tabular}{|c|c|}
\hline Demographics & No. $(\%)$ \\
\hline \multicolumn{2}{|l|}{ Age at initiation of dialysis } \\
\hline$<25 y$ & $420(1.50)$ \\
\hline $25-45$ y & $2,355(8.51)$ \\
\hline $45-65$ y & $7,356(26.59)$ \\
\hline $65-75 y$ & $8,056(29.12)$ \\
\hline$\geq 75$ y & $9,487(34.29)$ \\
\hline \multicolumn{2}{|l|}{ Sex } \\
\hline Men & $17,709(64.01)$ \\
\hline Women & $9,933(35.99)$ \\
\hline \multicolumn{2}{|l|}{ Type of dialysis } \\
\hline Hemodialysis & $23,704(85.70)$ \\
\hline Peritoneal dialysis & $3,938(14.30)$ \\
\hline \multicolumn{2}{|l|}{ Primary kidney disease } \\
\hline Congenital/inherited & $2,033(7.35)$ \\
\hline Diabetic nephropathy & $4,943(17.87)$ \\
\hline Primary glomerulonephritis & $3,185(11.51)$ \\
\hline Other & $1,223(4.42)$ \\
\hline Pyelonephritis and interstitial nephritis & $2,294(8.29)$ \\
\hline Systemic diseases & $1,495(5.40)$ \\
\hline Unknown or missing & $5,597(20.23)$ \\
\hline Vascular nephropathy & $6,894(24.92)$ \\
\hline \multicolumn{2}{|l|}{ Comorbid conditions } \\
\hline Heart disease & $5,497(19.87)$ \\
\hline Cerebral vascular disease & $1,927(6.97)$ \\
\hline Peripheral vascular disease & $2,895(10.14)$ \\
\hline Diabetes mellitus & $6,482(23.43)$ \\
\hline Liver disease & $2,337(8.45)$ \\
\hline Cancer & $2,669(9.65)$ \\
\hline Hypertension & $8,047(29.09)$ \\
\hline
\end{tabular}


Table 2. Relative Survival per Follow-up Interval

\begin{tabular}{|c|c|c|c|c|c|c|c|}
\hline \multirow[b]{2}{*}{ Time on Dialysis } & \multirow[b]{2}{*}{ No. } & \multicolumn{3}{|c|}{ Survivala } & \multicolumn{3}{|c|}{ Mortality Rate (/100 py) } \\
\hline & & Observed & Expected & Relative & Observed & Expected & Excess \\
\hline $3 \mathrm{mo}$ & 27,659 & $0.94(0.93-0.95)$ & 0.99 & $0.95(0.94-0.95)$ & 24.63 & 3.15 & 21.49 \\
\hline $6 \mathrm{mo}$ & 25,228 & $0.90(0.89-0.91)$ & 0.98 & $0.91(0.90-0.91)$ & 19.41 & 3.12 & 16.30 \\
\hline $1 \mathrm{y}$ & 23,337 & $0.83(0.82-0.83)$ & 0.97 & $0.85(0.84-0.86)$ & 15.66 & 3.08 & 12.60 \\
\hline $2 y$ & 19,901 & $0.72(0.71-0.73)$ & 0.94 & $0.77(0.76-0.77)$ & 13.94 & 3.04 & 10.90 \\
\hline $3 y$ & 14,343 & $0.62(0.61-0.63)$ & 0.91 & $0.69(0.67-0.69)$ & 14.51 & 3.12 & 11.39 \\
\hline $4 y$ & 10,016 & $0.55(0.54-0.55)$ & 0.88 & $0.62(0.61-0.63)$ & 13.42 & 3.22 & 10.19 \\
\hline $5 y$ & 6,952 & $0.47(0.46-0.48)$ & 0.85 & $0.56(0.55-0.56)$ & 14.22 & 3.28 & 10.94 \\
\hline
\end{tabular}

Note: Expected survival corresponds to survival drawn from the general population. Expected mortality is the mortality of a subset of individuals in the general population comparable to dialysis patients.

Abbreviation: py, person-year.

aWhen provided, $95 \%$ confidence intervals are shown in parentheses.

on the sex and age of the patient and year of registration, was obtained. The probabilities of each follow-up interval were multiplied to obtain the expected cumulative survival $\left(C P^{*}\right)$.

As a last step, interval-specific and cumulative relative survival ratios $(R$ and $C R$ ) were calculated as the ratios of the observed and expected interval-specific and cumulative survivals: $R=p / p^{*}$ and $C R=C P / C P^{*}$

Excess mortality rate (EMR) could be obtained easily from the difference between observed $(d)$ and expected deaths $\left(d^{*}\right)$ (also obtained from the Italian life table) divided by person-time at risk (y) in each interval $(i): E M R_{i}=d_{i} / y_{i}-d^{*}{ }_{i} / y_{i}$.

Relative survival and the excess mortality rate are estimated here according to the Ederer II method, ${ }^{8}$ in which matched individuals are treated as being at risk until the corresponding patient dies or is censored.

In the relative survival model, piecewise constant hazards are assumed. This treats the number of deaths in each interval as a Poisson process. In this way, by using a Poisson assumption for the observed number of deaths, the model may be estimated in the framework of generalized linear models. ${ }^{9}$ The exponentiated coefficient estimates of the Poisson model give estimations of the ratios between observed and expected deaths and thus may be interpreted as excess hazard ratios, also known as relative excess risks. This comparative measure is based solely on the component of risk due to the exposures because it removes the background risk. ${ }^{10}$ Goodness of fit was assessed using the deviance Pearson $\chi^{2}$ statistics.

Statistical analysis was performed using Stata, version 11 (StataCorp, www.stata.com).

\section{RESULTS}

The IDTR is a collection of 17 regional registries. In January 2000 to December 2008, a total of 45,427 individuals started either hemodialysis or peritoneal dialysis therapy. Because only 8 of the 17 regions were able to provide complete follow-up data, only the 27,642 patients belonging to these regions were considered. They constituted $61 \%$ of the full data set. The percentage of coverage in these 8 regions was $91 \%$.
Figure 1. The course of observed, expected, and relative survival during 8 years of follow-up calculated using the Ederer II method.

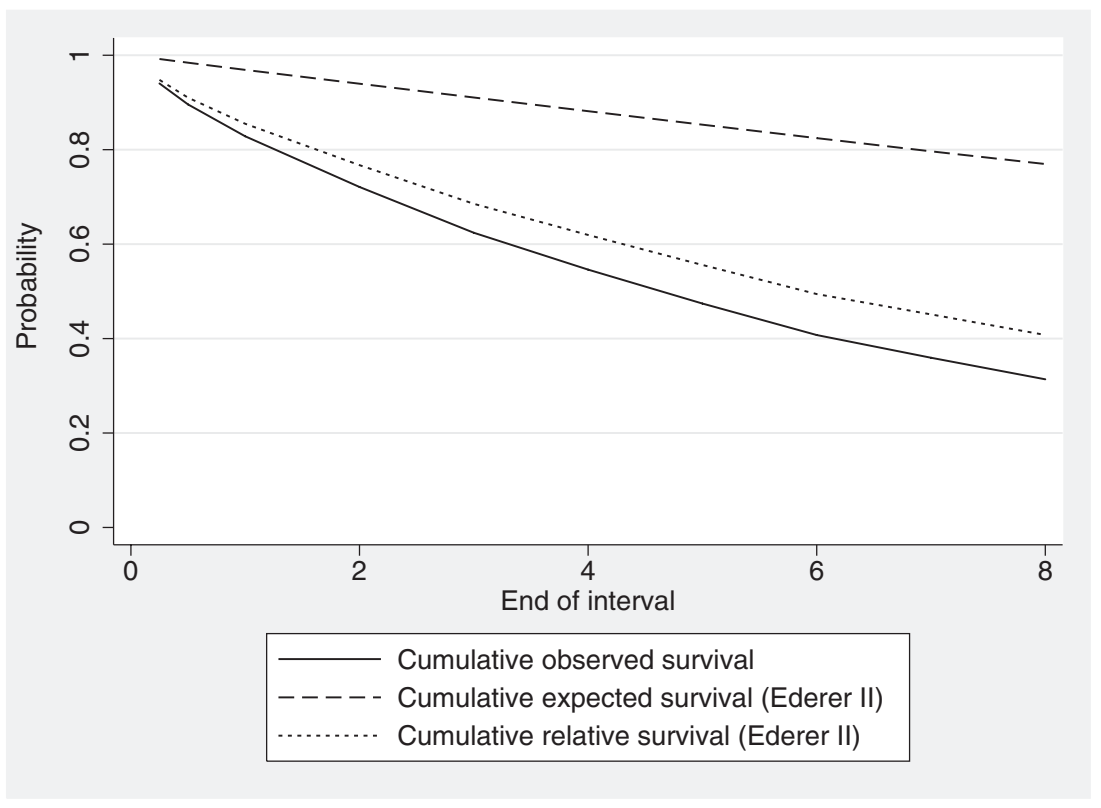


Table 3. Five-Year Relative Survival by Age Category

\begin{tabular}{|c|c|c|c|c|c|c|c|}
\hline \multirow[b]{2}{*}{ Age Category } & \multirow[b]{2}{*}{ No. } & \multicolumn{3}{|c|}{ Survivala } & \multicolumn{3}{|c|}{ Mortality Rate (/100 py) } \\
\hline & & Observed & Expected & Relative & Observed & Expected & Excess \\
\hline$<25$ y & 420 & 0.87 & 0.998 & $0.87(0.80-0.92)$ & 3.95 & 0.05 & 3.9 \\
\hline $25-45 y$ & 2,355 & 0.87 & 0.994 & $0.88(0.86-0.90)$ & 2.92 & 0.12 & 2.8 \\
\hline $45-65 y$ & 7,356 & 0.66 & 0.964 & $0.65(0.67-0.70)$ & 9.21 & 0.81 & 8.4 \\
\hline $65-75 y$ & 8,056 & 0.46 & 0.881 & $0.52(0.50-0.54)$ & 14.76 & 2.76 & 12.0 \\
\hline$\geq 75$ y & 9,487 & 0.27 & 0.670 & $0.40(0.38-0.41)$ & 26.07 & 8.57 & 17.5 \\
\hline
\end{tabular}

Note: Expected survival corresponds to survival drawn from the general population. Expected mortality is the mortality of a subset of individuals in the general population comparable to dialysis patients.

Abbreviation: py, person-year.

aWen provided, 95\% confidence intervals are shown in parentheses.

Patient characteristics are listed in Table 1. Median age was 70.0 (25th-75th percentile, 58.7-77.7) years, and $64 \%$ of patients were men. During follow-up, $22,756(82.3 \%)$ patients were treated with only hemodialysis; 3,265 (11.8\%), with only peritoneal dialysis; and 1,621 (5.9\%), with both hemodialysis and peritoneal dialysis. There were 11,616 deaths in 74,104 years at risk, determining a crude mortality rate during the study period of 15.68 deaths/100 patient-years (95\% confidence interval [CI], 15.39-15.96). Median survival time was 4.6 (95\% CI, 4.5-4.7) years.

Five-year observed and expected survivals were $47.4 \%$ and $85.0 \%$, respectively, yielding a relative survival estimate of $55.6 \%$ (95\% CI, 54.7\%-56.5\%). In other words, survival was less than expected for the general population by $44.4 \%$ (Table 2; Fig 1). Fiveyear relative survival was $56.8 \%(95 \% \mathrm{CI}, 55.6 \%$ $57.9 \%$ ) in men and $53.5 \%$ (95\% CI, 52.1\%-55.0\%) in women. As listed in Table 3, relative survival largely differed according to age category, being particularly low in the 2 oldest groups. Five-year relative survival was $55 \%$ (95\% CI, 54\%-56\%) in hemodialysis patients and 58\% (95\% CI, 56\%-60\%) in peritoneal dialysis patients.

The excess mortality rate did not stay constant over the time elapsed since dialysis therapy start. As shown in Table 2 and Fig 2, the excess mortality rate peaks at 21 deaths/100 patient-years at 3 months, decreases to 16 deaths/100 patient-years at 6 months, then reaches a plateau after 1 year, remaining relatively constant at around 10 deaths $/ 100$ patient-years until year 8 . The decrease in excess mortality rate was similar for men and women (Fig 3), suggesting that the first-year excess of deaths is independent of sex.

In Fig 4, mortality rate excess by age category is shown. It remains relatively stable over time in patients younger than 65 years, but decreases in the first 6 months in patients older than 65 years.

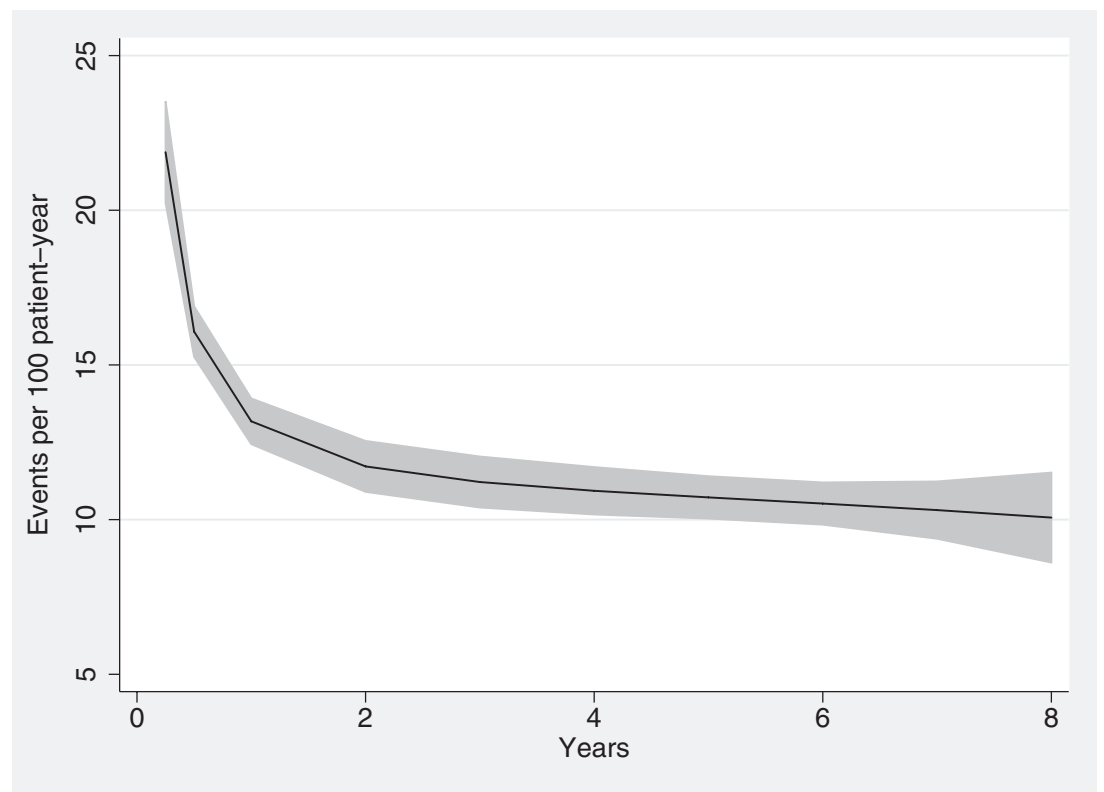

Figure 2. Time course of excess mortality rate since dialysis therapy initiation. Gray region marks $95 \%$ confidence bands. 


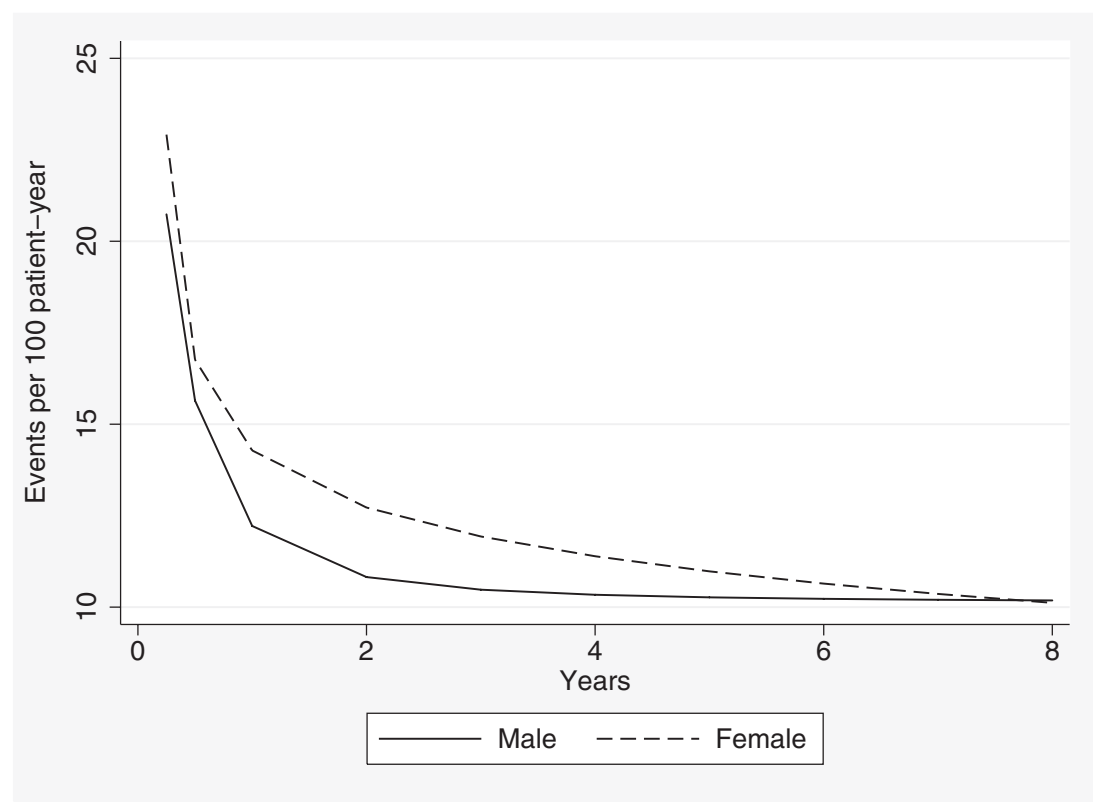

Figure 3. Excess mortality rate stratified by sex.

The excess mortality rate stratified by primary kidney disease is shown in Fig 5. The increase in excess mortality in the earliest period after starting dialysis therapy was observed in mainly 2 diagnostic categories: systemic disease and miscellaneous categories. In the systemic disease category, $39 \%$ of patients had multiple myeloma, and in the miscellaneous category, $33 \%$ of patients had kidney neoplasms; thus, many early deaths occur in patients affected by cancer.

The excess mortality time trend differed, showing an initial peak with a rapid decrease in hemodialysis and a modest progressive increase in peritoneal dialysis (Fig 6).
Excess mortality was modeled using Poisson regression in order to examine the possible determinants of excess hazard ratios, also known as relative excess risks. Table 4 lists unadjusted and adjusted relative excess risks. Patients who survived the first year had lower relative excess risk. Older age, systemic diseases, and diabetes had the strongest association with excess mortality. As listed in Table 5, which reports the interaction between follow-up period and type of dialysis, peritoneal dialysis was associated with lower relative excess risk in only the first year of treatment, but since the second year, relative excess risk was higher than in hemodialysis.

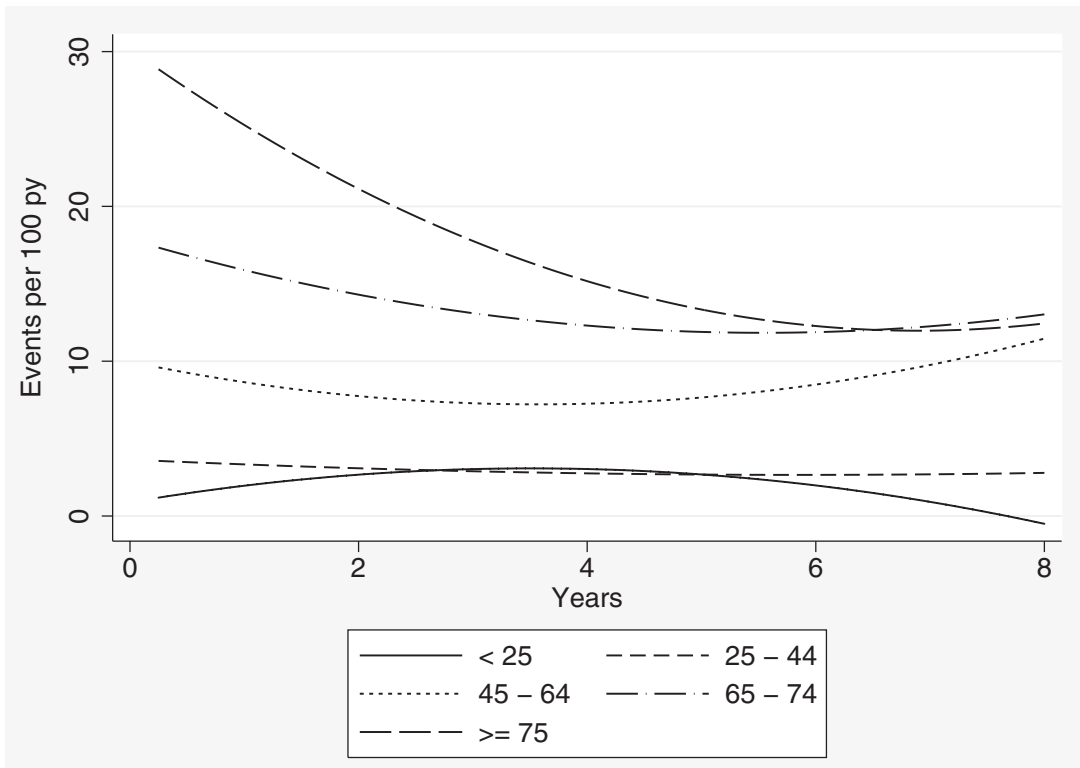

Figure 4. Excess mortality rate stratified by age category. Abbreviation: py, patient-year. 


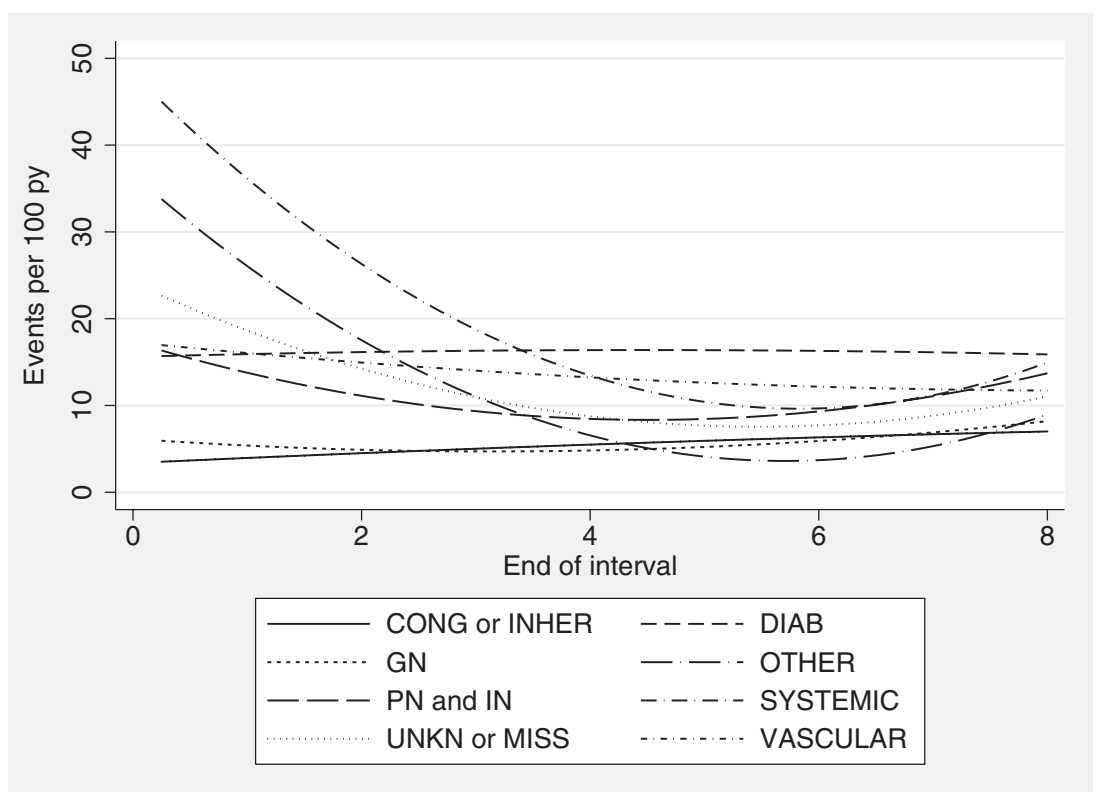

Figure 5. Excess mortality rate according to primary kidney disease. Abbreviations: CONG or INHER, congenital or inherited kidney diseases; DIAB, diabetic nephropathy; GN, primary glomeruIonephritis; OTHER, other kidney diseases; PN and IN, pyelonephritis and interstitial nephritis; py, patient-year; SYSTEMIC, systemic diseases; UNKN or MISS, unknown or missing diagnosis; VASCULAR, vascular kidney disease.
The assessed goodness of fit did not show evidence of lack of fit.

\section{DISCUSSION}

Relative survival is the standard measure of survival in cancer registries ${ }^{11,12}$ and has been proposed for use in other chronic diseases, such as cardiovascular disease ${ }^{13}$ and diabetes. ${ }^{14}$ Relative survival may be understood as the survival of a population affected by a particular disease under study, adjusted for all other competing causes of death. Dialysis patients, as part of the general population, are not isolated from the lifestyle risks and environmental and infectious determinants of diseases affecting the community as a whole. The possible risk factors relevant for dialysis patients may be split into 2 components: the background mortality typical of the population plus the excess due to dialysis. Some parallels exist between dialysis patients and patients with cancer: both are affected by chronic diseases, both have extended survival data collected about them, and for each of these 2 groups, there are annual registries that make such data available. This similarity encouraged us to broaden the use of relative survival methodology to the field of renal replacement therapy.

By using this methodology, we were able to estimate the prognosis of dialysis patients receiving longterm dialysis, showing that they experience survival

Figure 6. Excess mortality rate stratified by type of dialysis. Abbreviations: HD, hemodialysis; PD, peritoneal dialy-

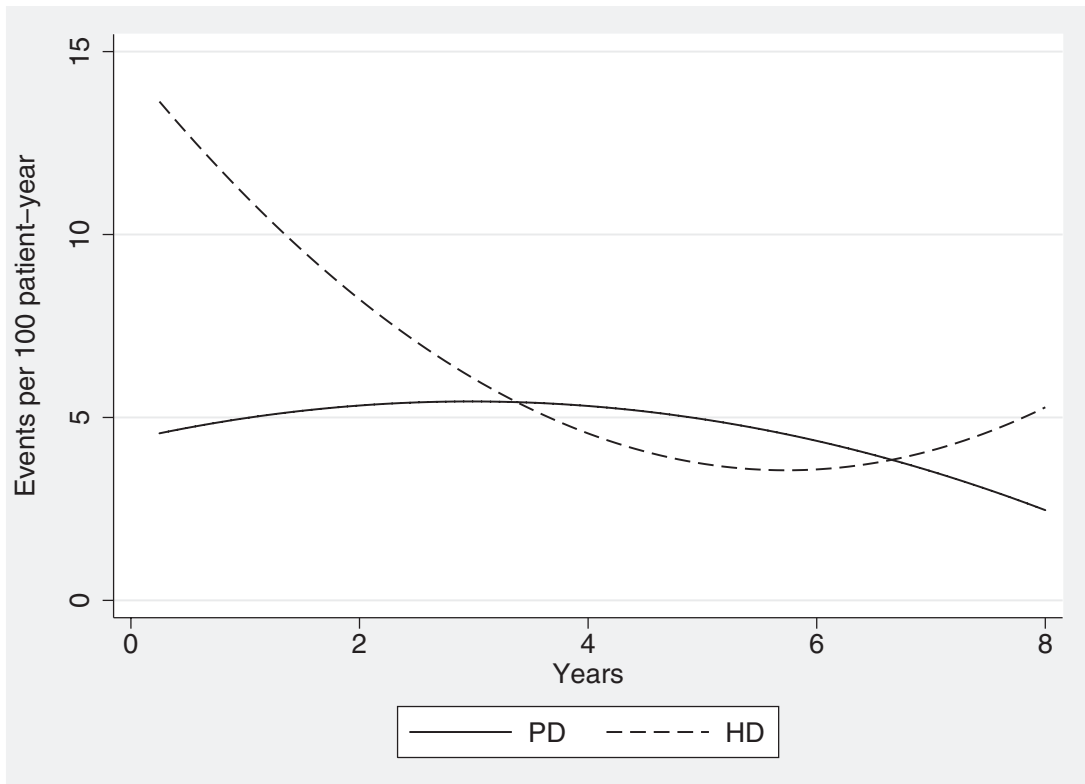
sis. 
Table 4. Unadjusted and Adjusted Relative Excess Risk by Patient Characteristics

\begin{tabular}{|c|c|c|c|c|}
\hline Variable & Deaths & Patients & Unadjusted RER & Adjusted RER \\
\hline \multicolumn{5}{|c|}{ Time elapsed since dialysis initiation } \\
\hline $1 \mathrm{y}$ & 4,495 & 27,659 & 1.00 (reference) & 1.00 (reference) \\
\hline $2 y$ & 2,372 & 19,901 & $0.67^{a}(0.62-0.71)$ & $0.74^{\mathrm{a}}(0.68-0.81)$ \\
\hline $3 y$ & 1,756 & 14,343 & $0.70^{\mathrm{a}}(0.65-0.75)$ & $0.57^{\mathrm{a}}(0.52-0.62)$ \\
\hline $4 y$ & 1,132 & 10,016 & $0.63^{a}(0.57-0.69)$ & $0.48^{\mathrm{a}}(0.44-0.52)$ \\
\hline $5 y$ & 811 & 6,952 & $0.67^{\mathrm{a}}(0.61-0.74)$ & $0.49^{\mathrm{a}}(0.45-0.54)$ \\
\hline $6 y$ & 562 & 4,565 & $0.77^{\mathrm{a}}(0.68-0.86)$ & $0.46^{\mathrm{a}}(0.42-0.51)$ \\
\hline $7 y$ & 280 & 2,867 & $0.58^{\mathrm{a}}(0.49-0.69)$ & $0.49^{a}(0.43-0.55)$ \\
\hline $8 y$ & 155 & 1,597 & $0.67^{\mathrm{a}}(0.54-0.82)$ & $0.58^{\mathrm{a}}(0.51-0.66)$ \\
\hline \multicolumn{5}{|l|}{ Age category } \\
\hline$<25$ y & 24 & 410 & 1.00 (reference) & 1.00 (reference) \\
\hline $25-45 y$ & 209 & 2,355 & $1.21(0.79-1.86)$ & $1.26(0.82-1.94)$ \\
\hline $45-65 y$ & 1,968 & 7,356 & $3.37^{\mathrm{a}}(2.24-5.09)$ & $3.23^{\mathrm{a}}(2.14-4.88)$ \\
\hline $65-75 y$ & 3,689 & 8,056 & $5.84^{\mathrm{a}}(3.88-8.78)$ & $5.09^{a}(3.37-7.69)$ \\
\hline$\geq 75 y$ & 5,673 & 9,482 & $8.81^{\mathrm{a}}(5.85-13.25)$ & $7.25^{\mathrm{a}}(4.8-10.95)$ \\
\hline \multicolumn{5}{|l|}{ Sex } \\
\hline Men & 6,996 & 17,706 & 1.00 (reference) & 1.00 (reference) \\
\hline Women & 4,267 & 9,953 & $1.15^{\mathrm{a}}(1.09-1.21)$ & $1.08^{a}(1.03-1.14)$ \\
\hline \multicolumn{5}{|l|}{ Primary renal disease } \\
\hline Congenital/inherited & 414 & 2,033 & 1.00 (reference) & 1.00 (reference) \\
\hline Diabetes & 2,334 & 4,943 & $4.37^{\mathrm{a}}(3.69-5.16)$ & $2.91^{\mathrm{a}}(2.50-3.38)$ \\
\hline Primary glomerulonephritis & 721 & 3,185 & $1.20(0.98-1.46)$ & $1.19^{a}(1.00-1.42)$ \\
\hline Others & 548 & 1,223 & $4.17^{\mathrm{a}}(3.44-5.05)$ & $2.78^{\mathrm{a}}(2.34-3.30)$ \\
\hline Pyelonephritis & 935 & 2,293 & $2.89^{a}(2.41-3.46)$ & $2.02^{\mathrm{a}}(1.71-2.37)$ \\
\hline Systemic diseases & 869 & 1,495 & $6.91^{\mathrm{a}}(5.79-8.25)$ & $5.93^{\mathrm{a}}(4.29-5.90)$ \\
\hline Unknown & 2,444 & 5,594 & $3.45^{\mathrm{a}}(2.91-4.09)$ & $2.38^{a}(2.05-2.77)$ \\
\hline Vascular diseases & 3,345 & 6,893 & $3.81^{\mathrm{a}}(3.22-4.50)$ & $2.25^{\mathrm{a}}(1.94-2.62)$ \\
\hline \multicolumn{5}{|l|}{ Comorbid conditions } \\
\hline Ischemic heart disease & 1,561 & 3,256 & $1.24^{\mathrm{a}}(1.16-1.32)$ & $1.08^{a}(1.01-1.17)$ \\
\hline Heart failure & 1,084 & 2,239 & $1.33^{a}(1.23-1.43)$ & $1.17^{\mathrm{a}}(1.08-1.26)$ \\
\hline Cerebral vascular disease & 1,004 & 1,927 & $1.33^{\mathrm{a}}(1.23-1.44)$ & $1.14^{\mathrm{a}}(1.05-1.24)$ \\
\hline Peripheral vascular disease & 1,425 & 2,804 & $1.33^{a}(1.24-1.43)$ & $1.18^{\mathrm{a}}(1.09-1.27)$ \\
\hline Liver disease & 394 & 923 & $1.08(0.96-1.22)$ & $1.15^{a}(1.02-1.30)$ \\
\hline Cancer & 1,169 & 2,337 & $1.32^{\mathrm{a}}(1.22-1.42)$ & $1.13^{\mathrm{a}}(1.04-1.21)$ \\
\hline Hypertension & 2,591 & 8,045 & $0.64^{a}(0.60-0.67)$ & $0.60^{\mathrm{a}}(0.56-0.63)$ \\
\hline
\end{tabular}

Note: RER of death with $95 \%$ confidence intervals. RER is analogous to relative risk ratio when excess mortality ratio models are built using Poisson regression.

Abbreviation: RER, relative excess risk.

asignificant RERs $(P<0.05)$.

of $55 \%$ at 5 years in comparison to the general population. To our knowledge, this is the first time that dialysis patients' prognosis has been measured by determining its relationship to background survival.

This method offers additional advantages because relative survival makes dialysis patients' outcomes comparable between different countries and health care systems and between different chronic diseases, allowing adjustment for the background mortality of the source population. ${ }^{15}$ For example, the US Renal Data System (USRDS) reports a higher mortality rate than European or Japanese registries, a difference that might be due at least in part to the respective source population: Japan has the highest life expectancy in the world, and almost all Western European countries have a higher life expectancy than the United States. ${ }^{16}$

The 5-year relative survival of dialysis patients is lower than that reported for regional breast cancer (84\%), regional colon cancer $(69.5 \%)$, and regional kidney cancer (62.7\%), but higher than that for chronic heart failure $(35 \%)$ and regional lung cancer $(24 \%){ }^{17}$ It is possible to rank the severity of different chronic diseases and compare their prognosis (Fig 7). From this perspective, dialysis patients need at least as much attention as cancer patients from health authorities and public opinion.

An interesting characteristic shown by the relative survival of dialysis patients is the absence of leveling 
Table 5. Relative Excess Risk by Time Elapsed Since Treatment Start for Peritoneal Dialysis Patients

\begin{tabular}{cc}
\hline Time Elapsed Since Dialysis Initiation & RER $(95 \%$ Cl) \\
\hline 1 y & $0.65^{\mathrm{a}}(0.57-0.74)$ \\
2 y & $2.13^{\mathrm{a}}(1.74-2.59)$ \\
$3 \mathrm{y}$ & $2.35^{\mathrm{a}}(1.89-2.93)$ \\
$4 \mathrm{y}$ & $2.62^{\mathrm{a}}(2.03-3.39)$ \\
$5 \mathrm{y}$ & $2.79^{\mathrm{a}}(2.06-3.79)$ \\
$6 \mathrm{y}$ & $2.24^{\mathrm{a}}(1.51-3.31)$ \\
$7 \mathrm{y}$ & $2.69^{\mathrm{a}}(1.49-4.84)$ \\
$8 \mathrm{y}$ & $2.15(0.98-4.71)$ \\
\hline
\end{tabular}

Note: Values for peritoneal dialysis patients are shown; hemodialysis patients constitute the reference group. RER is analogous to relative risk ratio when excess mortality ratio models are built using Poisson regression.

Abbreviations: $\mathrm{Cl}$, confidence interval; RER, relative excess risk.

aSignificant RERs $(P<0.05)$.

off over time. This implies that individuals receiving dialysis are never cured (at least in a statistical sense) because it is inevitable that they will die earlier than matched individuals in the general population. Contrary to what happens in neoplastic diseases, for which a proportion of patients are cured, dialysis patients never heal and thus no cure model may be proposed.

When modeling relative survival, we try to estimate directly the excess mortality experienced by patients receiving dialysis compared with that of the general population, thereby obtaining an estimate of net survival. In the first year of dialysis therapy, mortality is exceedingly high, identifying a subgroup of patients who do not benefit from it. These patients make up about $15 \%$ of the observed population. That dialysis patients undergo early high mortality during renal replacement therapy has been reported previously, ${ }^{18-21}$ but its description as mortality rate excess provides a more accurate measure because it is independent of the incidence of the disease. In many dialysis registries, the early mortality excess emerges only partially because these registries exclude the first 3 months of renal replacement therapy. ${ }^{1}$ It is estimated that patients not registered in the USRDS in the first 3 months are about $6 \%$ of the incident population. ${ }^{19}$ After the first year, there is a decrease in risk of excess mortality, an observation that is preserved even after adjustment for age, primary kidney disease, and comorbid conditions.

Early excess mortality has been reported in patients undergoing hemodialysis treatment only, likely due to selection bias because the most severely affected patients are not accepted into a peritoneal dialysis program. ${ }^{22}$ However, evidence is lacking that peritoneal dialysis is unsuitable for the sickest patients. Although (accounting for background mortality) relative excess risk is lower in the first year of peritoneal dialysis compared with hemodialysis therapy, it becomes at least twice that of hemodialysis from the second year onward. Thus, our comparison shows results similar to the CHOICE (Choices for Healthy Outcomes in Caring for ESRD) Study ${ }^{23}$; namely, an initial advantage survival given by peritoneal dialysis in the first year, followed by the hemodialysis advantage survival up to the seventh year. However, this result must be interpreted very cautiously because the censoring due to kidney transplant may not be uninformative, as required in survival analysis. Because

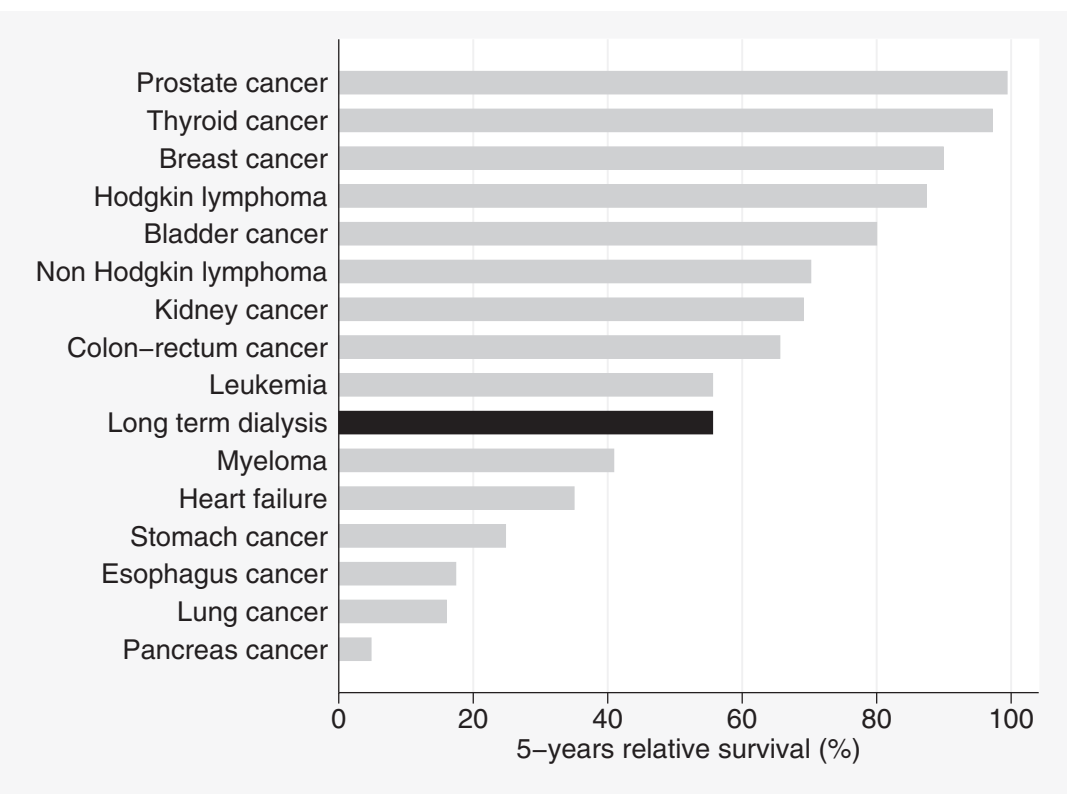

Figure 7. Comparison of 5-year relative survival of most important cancers with long-term dialysis and heart failure. Diseases are sorted by severity of prognosis. 
about $15 \%$ of peritoneal dialysis patients underwent transplant versus only $9 \%$ of hemodialysis patients, the mortality of peritoneal dialysis patients could have been overestimated. ${ }^{24}$

The impact of age on excess mortality risk is very relevant. Having taken into account that this measure is already adjusted for background mortality due to age itself, we showed that the relative excess risk of older patients is much higher. This means that the outcome of dialysis patients is more severe in fragile individuals.

Modeling of the excess mortality rate confirms results of the univariate analysis: the strongest predictors of excess mortality were age and some primary kidney diseases. The other covariates, such as sex and comorbid conditions, even if statistically significant, have only a marginal effect. It is worth emphasizing that women have a higher risk of death than men if background mortality is considered. This is another example of reverse epidemiology that may be found in dialysis patients.

There are 3 major limitations to this study. First, the cohort of patients available for our analysis makes up only about half the Italian patients who began receiving dialysis in the selected period. However, this pitfall is minimized by our taking into consideration only the Italian regions able to provide full data sets. Mortality rates were very similar and consistent within regions; thus, results probably are generalizable to the entire nation. Second, at least 2 regions had coverage less than $70 \%$ and one of them contributed substantially to the number of patients, thus possibly biasing results in an indeterminate way. However, a previous analysis performed on a single region with coverage near $100 \%$ gave similar results (Nordio M, Antonucci $\mathrm{F}$, unpublished data), suggesting that the bias, if present, should not be critical. Third, although the relative survival method allows us to override the competing risks derived from different causes of death that compete each other, it cannot treat competing risks arising from changes in renal replacement modality; for example, death on dialysis therapy prevented by kidney transplant.

In conclusion, this study emphasizes the usefulness of relative survival methodology in dialysis patients. This measure allows estimation of the prognosis of the disease and comparison of its severity with other chronic diseases. It provides a useful tool for comparing outcomes between dialysis registries because it takes into account the characteristics of the source population. The excess mortality rate seems a suitable measure to describe the trend of mortality in dialysis populations in a much more sensitive and informative way than that provided by the simple assessment of proportion of survivors. Because to our knowledge this is the first study that uses these measures in a dialysis registry, the worth of the methodology cannot be validated fully, but we hope that further studies will exploit its potential.

\section{ACKNOWLEDGEMENTS}

Members of the IDTR national commission are A. Molino* (Valle D’Aosta), M. Salomone* (Piemonte), G. Cappelli* (Liguria), F. Conte* and E. Arosio (Lombardia), F. Antonucci* (Veneto), B. Giacon* (Trentino Alto Adige), M. Adorati* and D. Romanini (Friuli Vebezia Giulia), A. Santoro* and E. Mancini (Emilia Romagna), A. Rosati* (Toscana), G.M. Frascà* and G. Gaffi (Marche), M. Standoli* (Umbria), M. Bonomini* and L. Di Liberato (Abruzzo), S. Di Giulio* (Lazio), M. Cirillo,* and G. Bilancio (Campania), F.P. Schena* and D. Torres (Puglia), F. Casino* (Basilicata), C. Zoccali* and C. Marino (Calabria), V. Sparacino* and V. Agnello (Sicilia), and A.M. Pinna* (Sardegna). Chairpersons are indicated with an asterisk; the remaining individuals are technical coordinators.

A version of this work was presented at the 48th European Renal Association-European Dialysis and Transplantation Association Congress, June 23-26, 2011; Prague, Czech Republic.

Support: None.

Financial Disclosure: The authors declare that they have no relevant financial interests.

\section{REFERENCES}

1. Collins AJ, Foley RN, Herzog C, et al. Morbidity and mortality. Am J Kidney Dis. 2010;55(suppl 1):S83-S94.

2. Stel VS, Kramer A, Zoccali C, Jager KJ. The 2007 ERAEDTA Registry Annual Report—a précis. NDT Plus. 2009;2:514521.

3. Mant J, Wilson S, Parry J, et al. Clinicians didn't reliably distinguish between different causes of cardiac death using case histories. J Clin Epidemiol. 2006;59:862-867.

4. Muntner P, He J, Hamm L, Loria C, Whelton PK. Renal insufficiency and subsequent death resulting from cardiovascular disease in the United States. J Am Soc Nephrol. 2002;13:745-753.

5. Nordio M, Postorino M, Casino F, Mancini E, Salomone M, Conte F. Standardization criteria to ensure the uniformity of data collection by the Italian Registry of Dialysis and Transplantation. Giornale Italiano Nefrologia. 2005;22:152-158.

6. Ederer F, Axtell LM, Cutler SJ. The relative survival rate: a statistical methodology. Natl Cancer Inst Monogr. 1961;6:101121.

7. ISTAT. Demography in figures. http://demo.istat.it/ index_e.html. Accessed July 4, 2011.

8. Ederer F, Heise H. Instructions to IBM 650 Programmers in Processing Survival Computations. Methodological Note No. 10. Bethesda, MD: End Results Evaluation Section, National Cancer Institute; 1959.

9. Dickman PW, Sloggett A, Hills M, Hakulinen T. Regression models for relative survival. Stat Med. 2004;23:51-64.

10. Suissa S. Relative excess risk: an alternative measure of comparative risk. Am J Epidemiol. 1999;150:279-282.

11. Dickman PW, Adami HO. Interpreting trends in cancer patient survival. J Intern Med. 2005;260:103-117.

12. Coleman M, Babb P, Damiecki P, et al. Cancer Survival Trends in England and Wales, 1771-1995: Deprivation and NHS Region. London, UK: Office for National Statistics; 1999.

13. Nelson CP, Lambert PC, Squire IB, Jones DR. Relative survival: what can cardiovascular disease learn from cancer? Eur Heart J. 2008;29:941-947. 
14. Sasaki A. Assessment of the new criteria for diabetes mellitus according to 10-year relative survival rates. Diabetologia. 1981;20:195-198.

15. Yoshino M, Kuhlmann MK, Kotanko P, et al. International differences in dialysis mortality reflect background general population atherosclerotic cardiovascular mortality. J Am Soc Nephrol. 2006; 17:3510-3519.

16. United Nations, Department of Economic and Social Affairs, Population Division. World Population Prospects: The 2006 Revision, Highlights. Working paper no. ESA/P/WP.202. 2007. http://un.org/esa/population/publications/wpp2006/WPP2006_ Highlights_rev.pdf. Accessed July 4, 2011.

17. Howlader N, Noone AM, Krapcho M, et al, eds. SEER Cancer Statistics Review, 1975-2008. Based on November 2010 SEER data submission, posted to the SEER web site 2011. Bethesda, MD: National Cancer Institute. http://seer.cancer.gov/csr/ 1975_2008/. Accessed December 4, 2011.

18. Khan IH, Catto GR, Edward N, MacLeod AM. Death during the first 90 days of dialysis: a case-control study. Am J Kidney Dis. 1995;25:276-280.

19. Soucle JM, McClellan WM. Early death in dialysis patients: risk factors and impact on incidence and mortality rates. J Am Soc Nephrol. 1996;7:2169-2175.
20. Tsakiris D, Jones EHP, Briggs JD, et al. Deaths within 90 days from starting renal replacement therapy in the ERA-EDTA Registry between 1990 and 1992. Nephrol Dial Transplant. 1999; 14:2343-2350.

21. Bradbury BD, Fissell RB, Albert JM, et al. Predictors of early mortality among incident US hemodialysis patients in the Dialysis Outcomes and Practice Patterns Study (DOPPS). Clin J Am Soc Nephrol. 2007;2:89-99.

22. Jager KJ, Korevaar JC, Dekker FW, Krediet RT, Boeschoten EW; Netherlands Cooperative Study on the Adequacy of Dialysis (NECOSAD) Study Group. The effect of contraindications and patient preference on dialysis modality selection in ESRD patients in The Netherlands. Am J Kidney Dis. 2004;43:891899.

23. Jaar BG, Coresh J, Plantiga LC, et al. Comparing the risk for death with peritoneal dialysis and hemodialysis in a national cohort of patients with chronic kidney disease. Ann Intern Med. 2005;143:174-183.

24. Verduijn M, Grootendorst DC, Dekker FW, Jager KJ, Cessie SI. The analysis of competing events like cause-specific mortalitybeware of the Kaplan-Meier method. Nephrol Dial Transplant. 2011;26:56-61. 